\title{
Pokušaj osnivanja Galerije moderne umjetnosti u Rijeci u razdoblju od 1932. do 1943. godine
}

Metzger-Šober, Branko

Source / Izvornik: Institucije povijesti umjetnosti : zbornik 4. kongresa hrvatskih povjesničara umjetnosti, 2019, 35 - 41

Conference paper / Rad u zborniku

Publication status / Verzija rada: Published version / Objavljena verzija rada (izdavačev PDF)

https://doi.org/10.31664/z4khpu.05

Permanent link / Trajna poveznica: https://urn.nsk.hr/urn:nbn:hr:254:312789

Rights / Prava: Attribution 4.0 International/Imenovanje 4.0 međunarodna

Download date / Datum preuzimanja: 2023-04-26

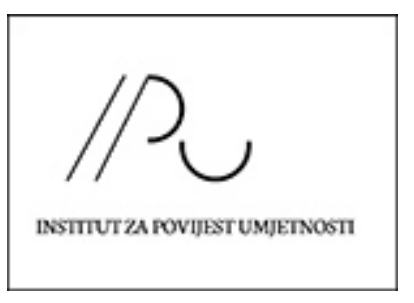

Repository / Repozitorij:

PODEST - Institute of Art History Repository 


\section{Pokušaj osnivanja Galerije moderne umjetnosti u Rijeci u razdoblju od I932. do I943. godine}

Postojeća literatura koja tretira karakter čina osnivanja Galerije likovnih umjetnosti u Rijeci svojim jednoznačnim i krajnje simplificiranim tumačenjem nameće potrebu reevaluacije i njegova dubljeg promišljanja te redefiniranja u plastičnom i realnom kontekstu povijesnih činjenica. Do sada redovito ponavljana konstrukcija političkoga diktata daleko je od objektivne i realne definicije događaja. Naime, očito je osnivanje Galerije likovnih umjetnosti r948. godine bilo plod kulturne politike tada mlade narodne vlasti, baš kao što je neuspjeli pokušaj osnivanja Galerije moderne umjetnosti $u$ okrilju Kraljevine Italije bio plod kulturno-političkih odrednica koje su joj prethodile. Iako je riječ o dvama dijametralno suprotnim društvenim uređenjima kojih temeljne odrednice pojedinačno i skupno znače međusobnu negaciju, njihovo opredjeljenje da u riječkoj regiji formiraju likovnu galerijsku instituciju vjerojatno je jedan od rijetkih zajedničkih ciljeva koji su dvije vlasti dijelile, dakako s različitim ideološkim poticajem. Premise istovrsne odluke za ostvarenje toga cilja bile su, dakle, potpuno različite, no zbog moguće kauzalne povezanosti zahtijevaju pomniju analizu.

U kontinuitetu događaja neosporno je kako je osnivanje Galerije likovnih umjetnosti u ranom poslijeratnom razdoblju znatno utjecalo na dalji razvoj likovnoga života grada Rijeke, regije i širega prostora bivše Jugoslavije. Ta institucija, a njezin rad bez prekida pratimo do danas, integralni je dio suvremenoga hrvatskog kulturnog krajolika, centar kontinuiranoga promicanja umjetničkih vrijednosti, sustavne edukacije, okupljanja i razvoja istinskih vrijednosti. Osnivački napori i brojni organizacijski dosezi usmjereni osnivanju Galerije moderne umjetnosti u razdoblju prije Drugoga svjetskog rata te s njima povezana intenzivna, programski ustrojena i snažno poticana likovno-izlagačka aktivnost u riječkoj regiji, elementi su koji su nedvojbeno pridonijeli formiranju temelja za galeriju koja je osnovana u mirnodopsko vrijeme.
Branko Metzger-Šober

samostalni istraživač branko.metzger@gmail.com

https://orcid.org/oooo-0oo2-o637-4I3X 
Razlozi osnivanja Galerije moderne umjetnosti do sada nisu sustavno istraživani. Štoviše, u poslijeratnom je razdoblju taj dio njezine povijesti marginaliziran, pa i zaboravljen. Navedeno se čini razumljivim s obzirom da se u doba komunističke vlasti nije spominjalo sve ono što je negativnim predznakom obilježilo talijansku vladavinu nad Rijekom. Ipak, ne može se zanijekati utjecaj toga razdoblja na likovni život grada, pa je takvo prepuštanje riječkoga međuratnog razdoblja zaboravu, koje traje do danas, nepravedno i neopravdano.

Bez obzira na nakane koje su u poticanju likovnoga života Rijeke u doba Italije bile sasvim sigurno vođene imperijalističkim težnjama, željom za tendencioznom interpretacijom svojih postignuća te asimilacijskim i programskim zadacima postavljenim pred umjetnost, iznimno bogatstvo likovnoga života grada do ratnih godina zahtijevalo je detaljno istraživanje, interpretaciju i otkidanje zaboravu. Grad Rijeka i uža regija koja mu je u razdoblju od I924. do I944. godine gravitirala, nisu bili obilježeni samo tadašnjom talijanskom vlašću-a njezin je utjecaj, bez obzira na mijene administrativnih međudržavnih odnosa i struktura lokalne vlasti, bio presudan-već su čuvali i baštinu ranijih povijesnih epoha. Međuratni je život Rijeke po svojim specifičnostima i refleksijama tadašnje talijanske nacionalne politike činio jedinstveno, gotovo endemsko područje, koje je u usporedbi s drugim hrvatskim krajevima u istom razdoblju obilježavalo više razlika negoli sličnosti.

Rijeka je za Kraljevinu Italiju imala posebno značenje. Italija je naime Rijeku smatrala ključnom geostrateškom točkom za prodor prema Dalmaciji, Crnoj Gori i Albaniji, u skladu sa željom pretvaranja cijeloga Jadrana i Sredozemlja u talijansko Mare nostrum. Osim toga, Rijeka je imala razvijenu rafineriju nafte, kakvu Italija nije imala. ${ }^{1}$ A tu su još bile tvornica torpeda, Hartera i ostala riječka vrlo razvijena teška i laka industrija. Sklapanjem Rimskoga sporazuma i Sporazuma o prijateljstvu 27. siječnja I924. godine, talijanska je vlada priznala suverenost Kraljevine sHs te joj je dodijeljena luka Baross i Delta. Kraljevina sHs je Rimskim sporazumom priznala suverenitet Kraljevine Italije nad Rijekom i njezinom lukom, ${ }^{2}$ a s tim je dokumentom Riječka Država i formalno prestala postojati. ${ }^{3}$ Granica prema Kraljevini sHs uspostavljena je na Rječini, a 22. veljače objavljen je Dekret o aneksiji Rijeke Kraljevini Italiji te je osnovana Kvarnerska provincija-Provincia del Carnaro sa sjedištem u Rijeci. ${ }^{4}$ Dana r6. ožujka r924. godine talijanski kralj Vittorio Emanuele III. došao je u prvi službeni posjet gradu Rijeci. Dočekao ga je Antonio Grossich kako bi vladar u Guvernerovoj palači i službeno proglasio priključenje Rijeke Kraljevini Italiji pod fašističkom vladavinom Benita Mussolinija. Konačno pripojenje Italiji, s balkona Guvernerove palače, objavio je Gaetano Giardini, simbolično uručivši talijanskom kralju ključeve grada Rijeke. ${ }^{5}$

Tako je Rijeka od imperijalne austrougarske luke, nekadašnjega velikog gospodarskog procvata i još većih planova razvoja, postala pogranična provincija Kraljevine Italije, okarakterizirana lučonošom talijanske kulture prema podunavskim zemljama. U novopriključenim dijelovima Kvarnerske

I Rafinerija nafte pored tvornice torpeda i ljevaonica bila je jedna od strateških industrija grada Rijeke, kojih se Mussolini htio dočepati. Riječka rafinerija nafte bila je najmodernija rafinerija nafte tadašnje Kraljevine Italije, na kojoj će se zasnivati cjelokupna buduća talijanska petrokemijska industrija.

2 GORAN MORAVČEK, Rijeka: prešućena povijest, nezavisno izdanje, Rijeka, I99o., 65.

3 Po D'Annunziovu odlasku situacija u Rijeci se zakomplicirala na razini političke svakodnevice. Fašistički je pokret preko legionara koji su ostali u gradu nakon D'Annunziova povlačenja unio nemir, onemogućavajući ekonomsku i političku konsolidaciju nove-riječke-države, koja je nastala I8. ožujka I92I. godine nakon ugovora koji su sklopili zapovjednici talijanskih četa u Opatiji s predstavnicima gradskoga vijeća Rijeke. Da bi se osiguralo osnovno funkcioniranje, trebalo je sastaviti ustavotvornu skupštinu Riječke Države, što je uspjelo u drugom pokušaju, dana 5. listopada I92I. godine, uz pozicioniranje autonomaša Zanelle i njegove većine u skupštini na čelne pozicije. Svijet vladavine autonomaša u ispunjenom snu Riječke Države trajao je kratko. Dana 3. ožujka I922. godine fašisti su okupirali Guvernerovu palaču, u kojoj im je tek nekoliko sati otpor pružao Zanella sa svojim najvjernijim suradnicima. Otpor je na kraju slomljen, fašisti su ušli u zgradu, a Zanella se sa suradnicima dao u bijeg. Po njegovu odlasku, I8. rujna I923. godine, osnovana je nova vlada na čelu s profesorom Attiliom Depolijem, koju će smijeniti Mussolini postavljajući za guvernera Gaetana Giardinija. Riječka Država, Stato di Fiume, ukida se 22. veljače I924. godine. Usp. GORAN MORAVČEK (bilj. 2), $70-72$.

4 Potpisivanjem Rimskoga ugovora 27. siječnja I924. godine osnovana je Kvarnerska provincija-Provincia del Carnaro koja potom politički suverenitet stječe 22. veljače r924. godine, na dan kada dolazi i do ukidanja Riječke Države-Stato di Fiume. Područna uprava pod nazivom Kvarnerska prefektura-Prefettura del Carnaro, imala je sjedište u Rijeci i bila najviša administrativna jedinica Provincije koja je, uz grad Rijeku, obuhvaćala još liburnijski dio Istre i Slovenije. Usp. IGOR ŽIC, Fiume e il Carnaro, u: Sušačka revija, 50/5I (2005.), 59-70, 6r.

5 Kralj Italije je I. rujna I943. godine prihvatio bezuvjetnu kapitulaciju Italije. Nakon kapitulacije Rijeku su okupirali Nijemci, koji su u grad ušli i4. rujna I943. godine te po svom dolasku smijenili riječku gradsku vlast i ukinuli riječku prefekturu. Godina r944. bila je obilježena bombardiranjem Rijeke savezničkom avijacijom, da bi početkom I945. godine krenule pripreme Jugoslavenske narodne armije za oslobođenje Rijeke i Hrvatskoga primorja od njemačke okupacije, što se i dogodilo 3. svibnja I945. godine. GORAN MORAVČEK (bilj. 2), 73. 
provincije talijanske su vlasti krenule s provođenjem niza sustavnih mjera kojima je cilj bio što skorije izjednačavanje političkoga i javnog života s onim u ostalim dijelovima Italije. Na neki je čudan način Rijeka sa zadovoljstvom prihvaćala ispunjenost novim gradskim događajima u umjetnosti-vibracijama koje su budile grad i davale osjećaj pripadnosti svijetu, kulturnoumjetničkom krugu Europe i Italije kao istinske velesile umjetnosti i kolijevke civilizacije. Iako je nedvojbeno kako je um intelektualaca onoga doba razaznavao kontekste vremena i osvajačke interese, osjećao sjenu političkih primisli, bio kritičan spram očitih i onih skrivenih namjera te duboko u sebi osuđivao dalekosežne težnje asimilaciji, ipak su živost koja je zavladala gradom te njegovo umjetničko buđenje općenito pružali osjećaj zadovoljstva.

Prva neostvarena prijeratna inicijativa utemeljenja Galerije moderne umjetnosti, kao nastavak prirodnoga procesa raznovrsne i iznimno bogate regionalne izlagačke i galerističke aktivnosti, promatra se kao logični korak u slijedu talijanskih nastojanja da se Rijeka učini prijestolnicom kulture na krajnjem istoku Kraljevine, koja bi širila svoje utjecaje prema podunavskim zemljama i središnjoj Europi. Jedan od načina da to postigne, pored poticanja lokalne sredine na likovno stvaralaštvo priređivanjem izložbi, bila je i ideja osnivanja Galerije moderne umjetnosti koja bi prezentirala vrhunska ostvarenja isključivo talijanskih umjetnika I9. i 2o. stoljeća i njihovih umjetničkih ostvarenja. Inicijator formiranja Galerije moderne umjetnosti u Rijeci i njezin glavni akter bio je Guido Asveri Bottussi, Riječanin sa stalnom adresom boravka u Milanu. Nažalost, podrobnijih podataka o njemu nemamo jer ne postoji biografija ili drugi prikaz Bottussijeva života i djela, no iz njegovih brojnih pisama, osim o aktivnostima, doznajemo ponešto i o njegovoj osobi. Za svoj stručni status tako sam ističe da je critico e restauratore di professione, conoscendo molto bene arte e artisti-kritičar i profesionalni restaurator, vrlo dobar poznavatelj umjetnosti i umjetnika. ${ }^{6}$

Korespondencija o osnivanju Galerije moderne umjetnosti traje od I934. do I943. godine, ne samo da je duga nego na kraju i naporna i mučna. Započeta je pismom koje je G. A. Bottussi uputio ministru Kraljevske kuće-Ministro della Real Casa, Alessandru Mattioliju Pasqualiniju u Rimu. ${ }^{7}$ Pismo je datirano I6. svibnja I934. godine i u njemu se prvi put spominje ideja o formiranju Galerije moderne umjetnosti u Rijeci, kao i način na koji bi se mogla provesti. Ideja je ministru Pasqualiniju prezentirana velikim riječima o novoj renesansi riječke umjetnosti i pokretanju novoga umjetničkog života, za kojim se osjeća velika potreba u gradu i Kvarnerskoj provinciji. Iz pisma je vidljivo da je riječ o odlučnoj gesti i samoinicijativnom zalaganju lokalpatriota koji bez osobnog interesa nastoji ostvariti cilj koji bi trebao biti na ponos Italije i talijanske Rijeke. Nadalje, u pismu Pasqualiniju G. A. Bottussi tvrdi da je ta njegova ideja naišla na potporu gradonačelnika Milana-vojvode Marcella Viscontija di Modronea, koji je obećao da će gradu Rijeci priskrbiti znatan broj umjetničkih djela u svrhu formiranja fundusa Galerije. Ta, kao i druga umjetnička djela
6 Hrvatski Državni arhiv Rijeka (HR-DARI), JU 6 , Predmet I-8-8, Belle arti-Gallerie-Musei-Antichita-Sovrintendenza, I930.-I944., kut. 33I, pismo Guido Asvero Bottussi-Il Ministro Conte Mattioli Pasqualini, Milano, I6. 5. I934.

7 HR-DARI, JU 6, Predmet I-8-8, Belle arti-GallerieMusei-Antichita-Sovrintendenza, I930-- I944., kut. 33I, pismo Guido Asvero Bottussi-Il Ministro Conte Mattioli Pasqualini, Milano, I6. 5. I934. 
koja bi darovale različite galerije i državne institucije, bila bi sakupljena u Milanu i dana na pohranu u Castello Sforzesco, pod skrb uvaženoga profesora Giorgia Nicodemija, ravnatelja arhiva i muzeja u Milanu, dok se za njih ne bi riješio trajan smještaj u Rijeci.

Kako bi akcija polučila što širi odaziv, G. A. Bottussi smatrao je da bi među prvim darovanim umjetničkim djelima za buduću riječku Galeriju, simbolički, barem jedno trebalo doći iz ruku kralja Vittorija Emanuelea III. ${ }^{8}$ Iz toga je razloga pismo i bilo upućeno baš ministru Pasqualiniju, osobi koja je u državnoj hijerarhiji bila najbliža kralju i kraljevskoj kući Savoya. Želja Bottussija bila je da ministar Pasqualini lobira kod kralja kako bi se on osobno založio i poduzeo potrebne korake koji bi podupirali Bottussijeva patriotska nastojanja iskazana inicijativom formiranja Galerije moderne umjetnosti u Rijeci. U uključivanju kralja Italije i njegovoj pretpostavljenoj donaciji Bottussi vidi gestu kojom bi se ostalim potencijalnim donatorima ukazalo na moralne vrijednosti koje će ih potaknuti u darivanju, a time projekt usmjeriti konačnom uspjehu. Uvidom u originale navedene prepiske, očito je da je G. A. Bottussi točno znao kako zainteresirati ključne osobe i potaknuti događanja koja će voditi postizanju njegova primarnog cilja-osnivanja Galerije moderne umjetnosti u Rijeci.

Riječki gradonačelnik Riccardo Gigante ${ }^{9}$ bio je djelomično upoznat s aktivnostima koje je započeo G. A. Bottussi, uvjeren u uspjeh vlastite inicijative. Tako doznaje da je Bottussi započeo prikupljati umjetnička djela u svrhu formiranja fundusa buduće Galerije moderne umjetnosti te da je već i sakupio velik broj. ${ }^{10} \mathrm{Na}$ kraju istoga pisma gradonačelnik je zaključio da će morati otići u Milano ne bi li se osobno uvjerio u ozbiljnost predmetne inicijative, vidjeti umjetničke radove i na licu mjesta provjeriti karakter i smjer događanja koja su, očito, zaobilazila riječke lokalne vlasti.

Ono na što bismo svakako trebali skrenuti pozornost jest činjenica da je inicijativa koju je pokrenuo Bottussi očito krenula bez ikakva saznanja grada. Bottussi je bez povratne informacije, samoinicijativno i na vlastitu ruku, u nadi da će inicijativa naići na pozitivan odjek kod riječkoga gradonačelnika, krenuo s prikupljanjem umjetničkih radova u svrhu stvaranja fundusa buduće Galerije moderne umjetnosti grada Rijeke. Pitanje koje se nameće jest upravo ono o legitimnosti od Bottussija poduzetih aktivnosti, odnosno samostalnog i suverenog obraćanja potencijalnim donatorima slika u ime grada Rijeke iako još za takvo što nije dobio privolu, odnosno potvrdu aktualnoga riječkog gradonačelnika, što će se poslije pokazati spornim.

Do susreta riječkoga gradonačelnika Riccarda Gigantea i G. A. Bottussija napokon je i došlo, što doznajemo iz entuzijastičnoga pisma kojega je u obliku izvještaja gradonačelnik g. lipnja I934. godine uputio riječkom prefektu. ${ }^{11} \mathrm{U}$ njemu stoji da su se u Milanu 7. lipnja sastali prof. Giorgio Nicodemi, G. A. Bottussi i riječki gradonačelnik R. Gigante po pitanju formiranja Galerije moderne umjetnosti u Rijeci. Slijedi vrlo detaljan opis njihova susreta i razgovora, iz kojega je razvidno da je G.
8 Kraljevi darovi: Amleto Cataldi, Bagnante; Filippo Carcano, Al pascolo; Filiberto Petiti, La valle del Santo; Pio Bottoni,Val d'Aosta (I doni artistici di S. M. il Re, La Vedetta d'Italia, Fiume, 26. 8. I934., 2). Darovi akademije i akademika: Felice Carena, La terrazza; Ferruccio Ferrazzi, Autorittrato; Cesare Vinzio, nep. djelo; Pietro Gaudenzi, nep. djelo; Angelo dall'Oca Bianca, nep. djelo (HR-DARI, JU 6, Predmet I-8-8, Belle arti-Gallerie-Musei-Antichità-Sovrintendenza, I930.-I944., kut. 33I, pismo G. A. Bottussi-Podestà C. Colussi-Comune di Fiume, Podestà, Milano I9. 2. I935.); Ardengo Soffici, nep. djelo; Luciano Zanelli, nep. djelo; Ettore Tito, Ritratto da donna; Luigi Nono, Piovano (HR-DARI, JU 6, Predmet I-8-8, Belle arti-Gallerie-Musei-Antichita-Sovrintendenza, I930.-r944., kut. 33I, Reale Accademia Italia-Prefetto di Fiume, Roma, 6. 6. r940.).

9 Riccardo Gigante imenovan je riječkim gradonačelnikom I930. i tu dužnost obavljao do r934. godine.

Io HR-DARI, JU 6, Predmet I-8-8, Belle arti-GallerieMusei-Antichita-Sovrintendenza, I930.- I944., kut. 33I, pismo R. Gigante-Prefetto del Carnaro, Fiume, 29. 5. I934.

II HR-DARI, JU 6, Predmet I-8-8, Belle arti-GallerieMusei-Antichita-Sovrintendenza, I930.-r944., kut. 33I, pismo R. Gigante-Prefetto del Carnaro, Fiume, 9. 6. I934. 
A. Bottussi na vlastitu ruku, bez konzultacija s gradskom upravom grada Rijeke, pokrenuo tu inicijativu prije nekoliko godina (I932. godine) ne bi li svome gradu priskrbio vrijednu zbirku slika najcjenjenijih talijanskih umjetnika ı. i 20. stoljeća. Nadalje se spominje Bottussijeva zamisao zasnovana na uvidu u činjenicu da grad Rijeka nema novca koji bi se mogao uložiti u otkupe umjetničkih djela, pa je jedini način bio da se ona pribave donacijama. Prefektu je pritom dano na znanje da je grad Milano kao „lombardijski grad koji je oduvijek znao podijeliti i poduprijeti patriotski duh Fijumana", ${ }^{12}$ odlučio u znak bratske pomoći darovati gradu Rijeci neka od umjetničkih djela Ig. i 20. stoljeća u svom vlasništvu, za buduću riječku galeriju. U zaključku pisma prvi se put spominje i izbor moguće lokacije za Galeriju moderne umjetnosti, koju je gradonačelnik Rijeke vidio u djelomično napuštenoj Villi Margherita, konzultirajući se o tome s profesorom G. Nicodemijem i G. A. Bottussijem. Riccardo Gigante složio se dakle s izborom lokacije, ocijenivši ga dobrim i logičnim, budući da se u to vrijeme odvijao i proces izmještanja i formiranja novoga sjedišta Gradskog muzeja. Kako je Gradski muzej posjedovao vrlo malu zbirku slika, u kojoj su dominirala uglavnom djela lokalnih slikara ne baš velike umjetničke vrijednosti i kvalitete, Riccardo Gigante, ujedno počasni konzervator Gradskoga muzeja, u toj je situaciji vidio mogućnost objedinjavanja Galerije moderne umjetnosti i Gradskoga muzeja u jednu instituciju. To se poslije pokazalo nepremostivom preprekom. Upravo dva ukazana problema, dakle, od kojih se jedan odnosi na samostalno djelovanje G. A. Bottussija bez autorizacije gradonačelnika grada Rijeke, a drugi na ideju da se gradska institucija muzeja objedini s Galerijom moderne umjetnosti kao njezina sastavnica, bit će glavne točke sporenja zbog kojih u konačnici Galerija moderne umjetnosti nije osnovana.

Novi gradonačelnik Rijeke Carlo Colussi, ${ }^{13}$ energičniji i odlučniji od svojega prethodnika Riccarda Gigantea, koji stupa na dužnost I935. godine, obustavlja sve Bottussijeve akcije nabavljanja umjetničkih djela, ne konzultiravši se prethodno s njim. ${ }^{14}$ Colussi će tako u prosincu r935. godine pokrenuti i pregovore s ravnateljem Moderne galerije i Banke Italije (Banca D'Italia) u Rimu, što ukazuje na novi pravac prikupljanja umjetničkih djela za Galeriju moderne umjetnosti u Rijeci, koja time postaje i riječkim pitanjem. ${ }^{15}$ Od Moderne galerije $u$ Rimu tražio je na posudbu djela talijanskih umjetnika Ig. i 20. stoljeća koja nisu izložena u stalnom postavu, a Banku potiče na razmišljanje o kratkoročnim posudbama umjetničkih djela iz njezine zbirke umjetnina Gualino. ${ }^{16}$

Gradonačelnik Carlo Colussi definitivno odbija ideju formiranja Galerije moderne umjetnosti kao zasebne institucije. Po takvoj odluci G. A. Bottussi je mišljenja da nema nikakvih obveza prepustiti pohranjena umjetnička djela u Milanu za njezino osnivanje. ${ }^{17}$ Kako se smatrao ovlaštenim kuratorom pohranjenih umjetničkih djela, smatra da se djela moraju vratiti njihovim donatorima jer do osnutka Galerije zbog kojih su donirana, prema novoj odluci riječkoga gradonačelnika Carla Colussija, neće doći. ${ }^{18}$
I2 Ibidem.

I3 Carlo Colussi biti će riječkim gradonačelnikom od I934. do r938. godine kada ga na istoj funkciji nasljeđuje Arturo de Maineri.

I4 HR-DARI, JU 6, Predmet I-8-8, Belle arti-GallerieMusei-Antichita-Sovrintendenza, I93o.-I944., kut. 33I, pismo podestà C. Colussi, Comune di Fiume-G. A. Bottussi, Fiume, 23.5. I935.

I5 HR-DARI, JU 6, Predmet I-8-8, Belle arti-GallerieMusei-Antichita-Sovrintendenza, I930.- I944., Kut. 33I, pismo podestà C. Colussi, Comune di Fiume, Roberto Papini, Roma, 23. I2. I935.

I6 HR-DARI, JU 6, Predmet I-8-8, Kabinetski spisi, kut.33I, spis: pismo R. Soprintendenza alle opere d'Antichita e d'Arte-Trieste-Ministero educazione Nazionale (nedatirani prijepis originalnog pisma zaveden pod brojem 3959).

I7 HR-DARI, JU 6, Predmet I-8-8, Belle arti-GallerieMusei-Antichita-Sovrintendenza, I930.-I944., kut. 33I, pismo G. A. Bottussi-Prefetto del Carnaro, Milano, I5. 5. I937.

I8 HR-DARI, JU 6, Predmet I-8-8, Belle arti-GallerieMusei-Antichita-Sovrintendenza, I930.- I944., kut. 33I, pismo G. A. Bottussi - A Sua Eccelenza il Capo del Governo, Milano, I4. 5. I937. 
Kako grad Rijeka nije olako želio odustati od umjetničkih djela deponiranih u Milanu, u listopadu r939. godine riječki ured Ministarstva unutarnjih poslova zatražio je pomoć od milanske policije. ${ }^{19}$ Nadležna osoba policije grada Milana po izvršenoj predmetnoj akciji prema Bottussiju obavještava riječke kolege kako je tijekom njihove intervencije G. A. Bottussi odbio predati tražena djela. Sa svrhom konačnoga rješavanja pitanja umjetničkih djela koja su se nalazila u depozitu kod G. A. Bottussija, državni podtajnik Kraljevine Italije izdao je naredbu da se poduzmu sve raspoložive radnje kako bi deponirana djela namijenjena budućoj Galeriji moderne umjetnosti u Rijeci došla do Konzervatorskoga zavoda u Trstu, koji ih je trebao zadržati u depozitu dok se u Rijeci ne osnuje spomenuta institucija. ${ }^{20}$ Jednako se očitovao prema Bottussiju pismom od I. srpnja I940. godine, u kojem ga navodi da preda umjetnička djela Konzervatorskom zavodu u Trstu s obzirom da je dobio oslobađajući mandat od donatora, a time bio oslobođen i možebitne obveze čuvanja umjetnina.

Nakon ponovljenoga policijskog nadzora nad G. A. Bottussijem u srpnju 194I. godine u Milanu, G. A. Bottussi predao je samo umjetnička djela koja su bila darovi kralja Vittorija Emanuelea III. ${ }^{21}$ Odaslana su iz Milana u Trst, gdje su trebala biti pohranjena u Konzervatorskom uredu. Po mišljenju konzervatora, slanje umjetnina u Rijeku bilo je odveć riskantno zbog ratnih opasnosti te su one tijekom puta skrenute $u$ Codroipo-Passariano, pretpostavlja se u depo Ville Manin.. ${ }^{22}$ Potkraj I942. godine već povučenim umjetničkim djelima iz kraljeve donacije u Passarianu pridružila su se i djela $\mathrm{Il}$ Terrazzo Felicea Carene i Autoritratto Ferruccia Ferrazzija. ${ }^{23}$ Prema dostupnim izvorima, danas nemamo nikakvih sigurnih spoznaja o tome što se s tim umjetničkim djelima poslije dogodilo. Uspjelo se ući u trag samo dvama umjetničkim djelima, ${ }^{24}$ od kojih za jedno sa sigurnošću možemo tvrditi da je bilo namijenjeno formiranju Galerije moderne umjetnosti $u$ Rijeci, dok za drugo nismo u potpunosti sigurni. Oba se danas nalaze u zbirkama privatnih kolekcionara.

Kako u ova dva slučaja možemo govoriti o djelomičnom identificiranju djela iz fundusa namijenjena osnivanju riječke Galerije moderne umjetnosti, mogli bismo pretpostaviti da su umjetnička djela iz kraljeve donacije te ona koja su bila dar talijanskih akademika, privremeno deponirana u Passarianu, nakon završetka rata razdvojena i usmjerena na razne destinacije. Iz navedenoga se može zaključiti da se nakon Drugoga svjetskog rata ta umjetnička djela, koja su uz nekoliko dodatnih sanduka arheologije i umjetnina riječkoga Gradskog muzeja bila spakirana i odnesena u smjeru Italije, po prestanku ratnih opasnosti nisu vratila u Rijeku. Uzrok tomu očigledno je bila promjena vlasti u Rijeci. Talijani nakon Drugoga svjetskog rata više nisu imali nikakvu jurisdikciju nad aneksijom prigrabljenim teritorijem, koji je po završetku Drugoga svjetskog rata ušao u sastav Federativne Narodne Republike Jugoslavije i tako bio vraćen matici Hrvatskoj. Uspostavom novih odnosa očito je da se Talijani nisu osjećali obveznima vratiti umjetnička djela koja su nekoć pripadala gradu Rijeci
I9 HR-DARI, JU 6, Predmet I-8-8, Belle arti-GallerieMusei-Antichita-Sovrintendenza, I930.- I944., kut. 33I, pismo Questura Milano-Questura Fiume, Milano, 2I. Io. I939.

20 HR-DARI, JU 6, Predmet I-8-8, Belle arti-GallerieMusei-Antichita-Sovrintendenza, I930.-I944., kut.33I, pismo Presidenza del Consiglio dei Ministri-Prefetto di Milano-Prefetto di Trieste-Prefetto di Fiume, Roma, ı6. Iо. I940.

2I HR-DARI, JU 6, Predmet D-Io-28, Museo Civico, Acquisti diversi, Soprintendenza al Monumenti e alle Gallerie della Venezia Giulia e del Friuli-Podestà di Fiume, Trieste, I7. I. I94I.

22 HR-DARI, JU 6, Predmet D-Io-28, Museo Civico, Acquisti diversi, Elenco degli ogeti d'Arte e Quadri inviati, per disposizioni superiori a Codroipo (Villa Manin) Prov. di Udine.

23 HR-DARI, JU, 2-I9-67, Il Soprintendente-Al podestà di Fiume, Trieste, Io. 2. I94I.

24 Riječ je o slici Felicea Carene Il Terrazzo, za koju sa sigurnošću možemo tvrditi da je rad koji je bio dio nekadašnjega osnivačkog fundusa za Galeriju moderne umjetnosti u Rijeci, kao i rad Amleta Cataldija Bagnante, skulptura koju je donirao kralj Vittorio Emanuelea III. za iste potrebe. Njezina identifikacija nije u potpunosti sigurna zbog razlika $u$ visini postojeće (pronađene) i visine skulpture koja je zavedena $u$ pisanim dokumentima. 
pod njihovom privremenom jurisdikcijom, kao ni one umjetnine koje su Rijeci darovali njihov kralj Vittorio Emanuele III. i talijanski akademici.

U želji daljih istraživanja obratili smo se Konzervatorskom zavodu u Trstu, no nažalost, usprkos brojnim pokušajima i višestrukim kontaktima, nismo uspjeli doći do informacija od interesa za ovo istraživanje.

Opsežan istraživački rad na primarnim povijesnim izvorima donio je sustavni pregled i integraciju spoznaja o formiranju riječke galerije u međuratnom razdoblju. Obrađeni materijali znače doprinos razumijevanju jedinstvene povijesne pozicije Rijeke, koja je bila poligon preklapanja država, nacija i utjecaja do razine koja se može poistovjetiti s eksperimentalnim modelom u kojem su opće promjene testirane u iznimnim okolnostima nepobitnih utjecaja. Materijali koje smo obradili donose odgovore na niz dosad otvorenih pretpostavki o pokušaju osnivanja Galerije moderne umjetnosti u Rijeci te istodobno postavljaju temelje za buduća istraživanja usmjerena razrješenju preostalih dvojbi.

Tema je istražena u okviru izrade doktorske disertacije naslova „Međuratni povijesni kontekst osnivanja Galerije likovnih umjetnosti u Rijeci" (Sveučilište u Zadru, 20I5.).

\section{() (1)}

Pokušaj osnivanja Galerije moderne umjetnosti u Rijeci u razdoblju od ı932. do I943. godine/ Branko Metzger-Šober/CC BY / 4.0

DoI: https://doi.org/ıo.3r664/z4khpu.o5 